\title{
Determining the Effects of the Monitoring and Counseling in Addition to Standard Monitoring on the Abstinence after Quit Smoking: A Randomized Controlled Study
}

\author{
Aslı Güleșen² (D), Tülay Yavan' (D, Hatice Bebiș³ (D) \\ 'Department of Nursing, İzmir University of Economics, İzmir, Turkey \\ ${ }^{2}$ Turkish Armed Forces, Nursing, Ankara, Turkey \\ ${ }^{3}$ Faculty of Nursing, Near East University, Nicosia, Cyprus \\ ORCID IDs of the authors: T.Y. 0000-0003-3287-I487; H.B. 0000-000I-6217-9753; A.G. 0000-0002-4204-1746.
} Cite this article as: Gülessen A, Yavan T, Bebiș H. Determining the Effects of the Monitoring and Counseling in Addition to Standard
Monitoring on the Abstinence after Quit Smoking: A Randomized Controlled Study. Cyprus J Med Sci 2020; 5(I): 18-25.

\section{BACKGROUND/AIMS}

The aim of this study was to determine the effects of supplemental monitoring and counseling in addition to the standard monitoring during the treatment period on the abstinence behavior of smoking cessation center applicants.

\begin{abstract}
MATERIAL and METHODS
The randomized controlled study was conducted in the smoking cessation clinic as an intervention study. The study involved 67 participants. Data collection was implemented using the Descriptive Questions Form, Fagerström Test for Nicotine Dependence, Carbon Monoxide Monitoring Chart, and Self-Efficacy Questionnaire. After routine standard training and tests at the smoking cessation center, a total of six supplemental interviews were conducted in the intervention group by one of the researchers; these interviews were conducted one week before smoking cessation and one week and one, two, three, and six months after quitting. Two interviews were conducted in the control group for evaluation: one week before and six months after quitting.
\end{abstract}

\section{RESULTS}

After six months, $88.2 \%$ of the intervention group and $60.6 \%$ of the control group had stopped smoking. A statistically meaningful difference was found between the intervention and the control groups in terms of attending the standard monitoring. In the last interview, the self-efficacy score of the intervention group was significantly higher than that in the control group. Compared to the control group, the intervention group was 1.5 times more successful in smoking cessation at the end of the sixth month.

\section{CONCLUSION}

Those successful in smoking cessation must be monitored in frequent follow-ups simultaneously supported by physicians, nurses, and other health-care providers.

Keywords: Abstinence, counseling, monitoring, nursing, quit smoking

\section{INTRODUCTION}

Nicotine addiction is a very common addiction, and tobacco use has serious negative effects on human health and is one of the most significant preventable public health problems in the world (I). Interventions for smoking cessation include pharmacological and behavioral methods and other alternative approaches (2). Each year approximately two out of every three smokers make an attempt to quit (3). However, quitting is very difficult to achieve without any systemic support or program. Only $3 \%-5 \%$ of self-quitters achieved abstinence after a self-quit effort (4).

The greatest problem in smoking cessation is relapse. The relapse rate for smokers who attempt to quit on their own has been reported as $80 \%$ within the first month, with only $3 \%-5 \%$ individuals remaining abstinent at 6 months (5). Relapse generally occurs within the first three months. Although relapse is related to withdrawal symptoms in the early cessation period, psychological factors may play a more crucial role in the long term (6); therefore, a model focusing on cognitive-behavioral relapse prevention has been suggested (7). Interviews intended to prevent relapse and 
approaches to reward positive attitude were very effective in the attempting-to-quit phase. Frequent contact with healthcare providers is important to support the abstinence efforts. The clinical guidelines reported a strong relationship between the number of health care providers visits and the length of abstinence $(3,8)$. Pharmacotherapy, counseling, and behavioral support also increase quitting and abstinence rates (3, 8, 9). In addition, self-efficacy influences behavioral changes in smoking cessation efforts. Self-efficacy represents the self-confidence levels that cause individuals to resist smoking in many high-risk situations (10). The success of the intervention was markedly increased, if it was implemented in specialized smoking cessation clinics with close monitoring and appropriate motivational and psychological support (II).

Nurses are mainly involved in the smoking cessation campaigns and provide preventive and curative services in collaboration with other health-care professionals. There have been successful cessation interventions implemented by nurses in clinics and in other social contexts (12-16). Besides smoking cessation interventions, nurses have been involved in relapse prevention by monitoring smokers, during both the cessation attempt and the continuation phase $(17,18)$.

The aim of this study was to determine the effects of monitoring and counseling during the cessation period in addition to the routine monitoring performed during the treatment period on the abstinence behavior of smoking cessation center applicants.

\section{MATERIALS AND METHODS}

\section{Design and Participants}

This study was conducted in the smoking cessation clinic of the Cancer Early Diagnosis, Screening and Education Center (CEDSEC) between December 2012 and November 2013 as an intervention type and randomized controlled study. In Turkey, smoking cessation clinics are incorporated into the CEDSEC. Ethical approval was received from the Institutional Ethics Committee (|49|-1323-12/1648-4002). Research application approval was received from the Public Health Institution (Ministry of Health).

\section{Main Points:}

- In our study, we studied the effects of supplemental monitoring and counseling in addition to the standard monitoring during the treatment period on the abstinence behavior of smoking cessation center applicants.

- At the end of the six months, the self-efficacy score of the intervention group was significantly higher than that in the control group.

- The intervention group was 1.5 times more successful than the control group in smoking cessation.

- Individuals who have been successful in smoking cessation should be frequently monitored, and in follow-ups simultaneously supported by physicians, nurses, and other health-care providers.

- There is a need for longer-term, randomized controlled studies with larger sample groups.
The participants were individuals admitted to the smoking cessation program who were $>18$ years of age. Informed consent was obtained from all individual participants included in the study. Participants were assigned to the intervention or control groups by way of random closed-enveloped lottery. Participants were blinded to their assigned group, each of which consisted of 34 individuals. One individual from the control group was excluded after the first interview because they moved away from the area.

Data were collected by using the following forms:

- Descriptive Questions Form,

- Fagerström Test for Nicotine Dependence (FTND),

- Carbon monoxide (CO) Monitoring Chart, and

- Self-Efficacy Questionnaire (SEQ).

\section{Descriptive Questions Form}

This form was developed by the researchers in keeping with the related literature ( $1,4,6,8,10,12-15,17,18,21,22,25-27,31,34)$; it elicits individual characteristics and smoking behaviors.

\section{FTND}

FTND, developed in 1978 and revised in 1991, indicates the individual's nicotine dependence level (19). Uysal et al. (20) translated the scale into Turkish in 2004. They determined the Cronbach's alpha was 0.59 in a sample of Turkish smokers.

The FTND is composed of six questions, two scored " $0-3$ ", and four scored "0-I". Total scores vary from 0 to I0; 0 indicates no dependence, and 10 indicates the highest level of dependence. The FTND was routinely applied by physicians before education on "Effects of Tobacco on Health" to those who applied to the CEDSEC for smoking cessation. These test results were used in our study.

\section{COMonitoring Chart}

$\mathrm{CO}$ measurement is used to monitor those undergoing smoking cessation and to diagnose various pulmonary diseases (2I). CO levels of CEDSEC applicants for smoking cessation were routinely measured by the physician every monitoring visit. These measurement results have been used in our study.

\section{SEQ}

The SEQ, developed by Nicki et al. (10) in 1984, was adapted by Karanci in a Turkish sample of 174 smokers in 1992. Cronbach's alpha value was determined as 0.92. The SEQ assesses the subjects' perceptions of their ability to abstain from smoking in various situations. It contains 25 items, each rated on a five-point scale ranging from "not sure at all: I" to "very sure: 5 ". The scale total score varies between 25 and 125 points and a higher score indicates a greater ability to refrain from smoking (10). We obtained permission from Karanci by e-mail to use the SEQ. In our study, Cronbach's alpha value was 0.80 .

\section{Application}

A total of six interviews were performed with the intervention group members who also received standard care in the clinic. The researchers encouraged their continued participation in the standard monitoring. The individuals in the control group received only standard monitoring in the clinic on a voluntary ba- 
sis. For both groups, the measurements were conducted during the first and the last interviews. Participants were asked about their abstinence in the first, third, and sixth month. Figure I shows the application process in detail.

\section{Standard Monitoring:}

This monitoring was routinely implemented in the CEDSEC. Participants completed the FTND before education on "Effects of Tobacco on Health". Then, participants had a blood test, breath function test, and lung X-ray performed at the Chest Diseases Clinic. If nothing was amiss, the participants were provided with appropriate pharmacotherapy. Participants were given information about the medicine and cautioned about the early effects of quitting smoking and the importance of avoiding even minimal amounts of smoking. Their first $\mathrm{CO}$ measurement was also taken at this time. They were provided with the first three month supply of medicines, and at every control visit, $\mathrm{CO}$ levels were measured. During this period, the participants were required to attend a control visit in the first week, and in the first second, third, sixth, ninth, and twelfth months. For the standard monitoring, there were no attempts to make absent participants attend the control visits, and participants with $\mathrm{CO}$ levels $>5$ were excluded. After 12 months of monitoring, successful participants were no longer required to attend.

\section{Intervention Group}

Interviews were conducted as follows: 45 minute sessions of nurse counseling were provided in a quiet and appropriate room in the clinic by a qualified nurse in accordance with the principals of individual counseling.

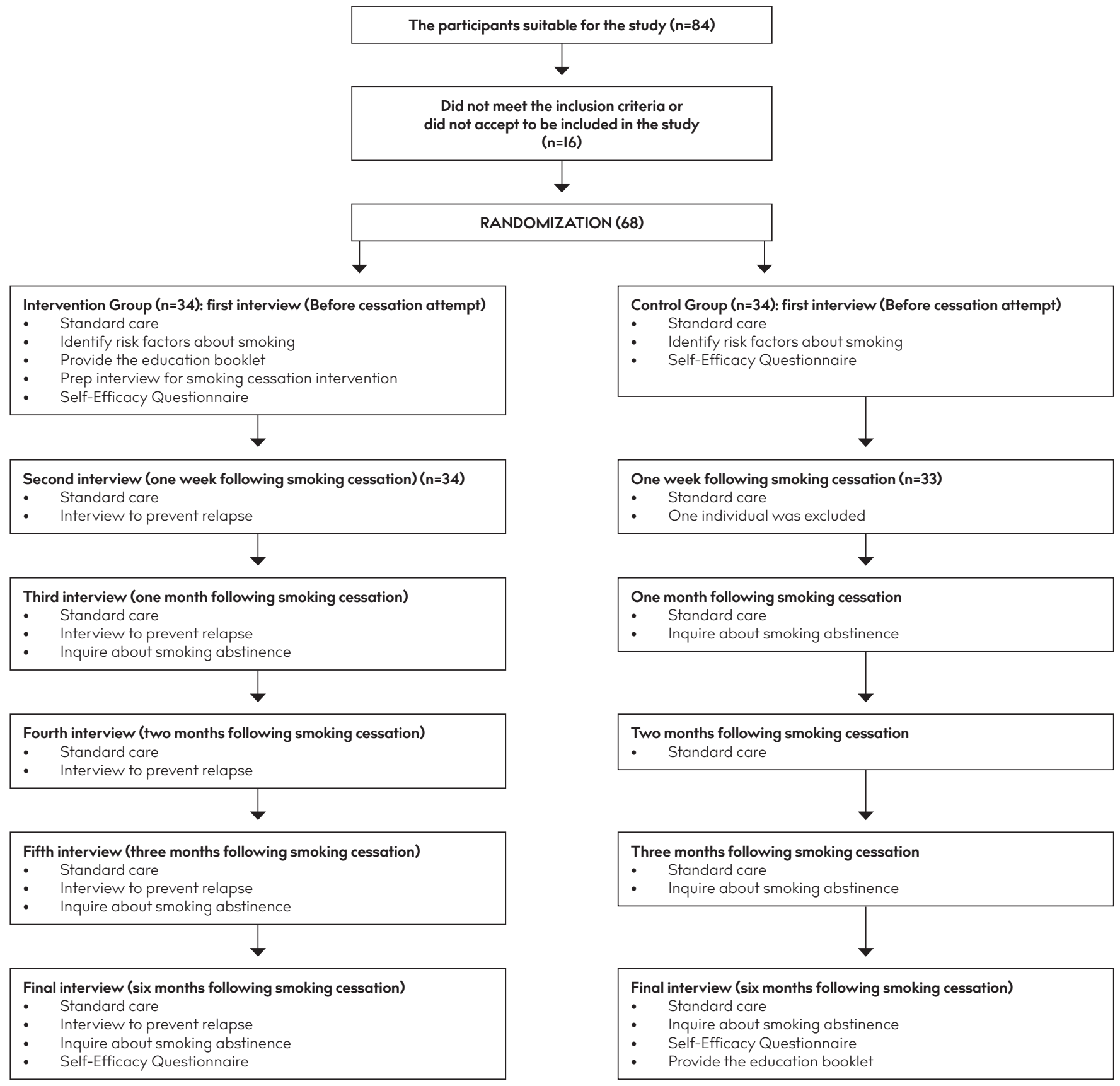

FIGURE I. Flow chart of the Study 


\section{Education Booklet}

An educational booklet, which provided information on the challenges of cessation, was prepared for those undertaking smoking cessation to support this endeavor. The booklet was provided in the first interview, and participants were asked to complete the "Smoking Cessation Diary" section.

\section{First Interview (Prep Interview)}

This was an interview to prepare the individual to quit smoking; it was conducted approximately one week before the smoking cessation date and determined the personal information and risk factors of the individual. Information about the education booklet was provided, and participants completed their "My Smoking Cessation Diary". No statistical analysis was applied to the diary as its aim was only to motivate and support the cessation efforts.

\section{Second Interview (High-Risk Period Monitoring)}

The first two weeks of the cessation period carry the greatest risk of relapse (3). Therefore, the second interview took place within a week, in order to prevent relapse.

\section{Third, Fourth, and Fifth Interviews (Relapse Prevention Moni- toring):}

Interviews to prevent relapse were repeated. In these interviews, participants who missed their control appointments were reminded of the appointments and invited by phone to attend. When participants missed appointments because of forgetfulness, shame, or failure, they were reminded that:

- Smoking one or two cigarettes did not mean that they had resumed smoking,

\begin{tabular}{|c|c|c|c|c|c|c|}
\hline \multirow[b]{2}{*}{ Characteristics } & \multicolumn{2}{|c|}{$\begin{array}{c}\text { Intervention } \\
\quad(n=34)\end{array}$} & \multicolumn{2}{|c|}{$\begin{array}{l}\text { Control } \\
(n=33)\end{array}$} & \multirow[b]{2}{*}{$X^{2}$} & \multirow[b]{2}{*}{$p$} \\
\hline & $\mathbf{n}$ & $\%$ & $\mathrm{n}$ & $\%$ & & \\
\hline \multicolumn{7}{|l|}{ Age } \\
\hline$\leq 45$ years & 14 & 41.2 & 12 & 36.4 & 0.163 & 0.686 \\
\hline$>45$ years & 20 & 58.8 & 21 & 63.6 & & \\
\hline \multicolumn{7}{|l|}{ Gender } \\
\hline Female & 18 & 52.9 & 17 & 51.5 & 0.014 & 0.907 \\
\hline Male & 16 & 47.1 & 16 & 48.5 & & \\
\hline \multicolumn{7}{|l|}{ Marital Status } \\
\hline Married & 27 & 79.4 & 29 & 87.9 & 0.875 & 0.350 \\
\hline Single/Widow & 7 & 20.6 & 4 & 12.1 & & \\
\hline \multicolumn{7}{|l|}{ Education level } \\
\hline$\leq$ Primary education & 9 & 26.5 & 15 & 45.5 & 2.625 & 0.269 \\
\hline Secondary education & 7 & 20.6 & 5 & 15.2 & & \\
\hline zHigher education & 18 & 52.9 & 13 & 39.4 & & \\
\hline \multicolumn{7}{|l|}{ Working status } \\
\hline Working & 10 & 29.4 & 10 & 30.3 & 1.185 & 0.553 \\
\hline Not working & 13 & 38. & 16 & 48.5 & & \\
\hline Retired & ॥ & 32.4 & 7 & 21.2 & & \\
\hline$X^{2}=$ Pearson Chi-Squar & & & & & & \\
\hline
\end{tabular}

- This was a learning process, and

- They should not smoke even the smallest amount.

\section{Last Interview (Evaluation Interview)}

Participants' smoking cessation statuses were evaluated. In this period, those who managed to quit were in the cessation phase. They were reminded of the continuing danger of relapse. Those in relapse risk were supported with cessation help and counseling.

\section{Control Group}

In the first interview, personal information and risk factors were determined for the control group. In the second and final interview, the smoking cessation status of the participants was evaluated. For ethical reasons, an educational booklet was also provided for this group at the end of the study.

\section{Statistical Analysis}

Statistical Package of Social Sciences 16.0 (SPSS, Inc., Chicago, IL, USA) was used for the data analysis. The results were assessed at the $95 \%$ confidence interval, with significance at $p<0.05$. For the descriptive statistics, variables determined by counting were stated as numbers and percent, and measured variables were stated as median ( \pm ) standard deviation, and "minimal"-"maximal". Normal distribution suitability of the continuous variables was evaluated with the one-sample Kolmogorov-Smirnov test. In analyzing the differences between the groups, for the normal distribution variables, Student $t$ test was used, and for the others, Mann-Whitney U test was used. In analyzing the differences within a group for the normal distribution variables, Paired samples ttest was applied, and for others, Wilcoxon test. Pearson chi-square test was used for the analysis of intermittent variables.

\section{RESULTS}

No statistically meaningful differences in demographics and smoking behavior were observed between the intervention and the control groups at the first interview $(p>0.05)$ (Table I).

The percent of participants who began smoking before age 18 years was $52.9 \%$ in the intervention group and $45.5 \%$ in the control group; $55.9 \%$ of the intervention group and $63.6 \%$ of the control group reported smoking for $>30$ years, and $38.2 \%$ of the intervention group and $42.4 \%$ of the control group reported smoking more than a pack per day. No previous attempts at smoking cessation were reported by $32.4 \%$ of the intervention group and $18.2 \%$ of the control group; $61.8 \%$ of the intervention group and $60.6 \%$ of the control group reported previously trying to quit by themselves. According to the FTND, $29.4 \%$ of the intervention group and $24.2 \%$ of the control group were in the very high dependence group (Table 2).

The intervention group attended an average of $5.47 \pm 1.16$ standard monitoring sessions, whereas the control group attended an average of $4.12 \pm 1.56(p<0.01)$.

An increase in the self-efficacy scores of all subjects in the study was found. At the last interview, the self-efficacy score of the intervention group was significantly higher than that in the control group $(p<0.05)$ (Table 3$)$. 
The intervention group stated that their desire to smoke was strongest "postprandial" and "when stressed" before cessation

\begin{tabular}{|c|c|c|c|c|c|c|}
\hline \multirow[b]{2}{*}{ Characteristics } & \multicolumn{2}{|c|}{$\begin{array}{c}\text { Intervention } \\
(n=34)\end{array}$} & \multicolumn{2}{|c|}{$\begin{array}{l}\text { Control } \\
(n=33)\end{array}$} & \multirow[b]{2}{*}{$X^{2}$} & \multirow[b]{2}{*}{$p$} \\
\hline & $\mathbf{n}$ & $\%$ & $\mathbf{n}$ & $\%$ & & \\
\hline \multicolumn{7}{|l|}{ Beginning age for smoking } \\
\hline$\leq 17$ years & 18 & 52.9 & 15 & 45.5 & 0.376 & 0.540 \\
\hline$\geq 18$ years & 16 & 47.1 & 18 & 54.5 & & \\
\hline \multicolumn{7}{|l|}{ Cigarettes per day } \\
\hline$\leq$ l pack (20 pieces) & 21 & 61.8 & 19 & 57.6 & 0.122 & 0.727 \\
\hline >I pack (20 pieces) & 13 & 38.2 & 14 & 42.4 & & \\
\hline \multicolumn{7}{|l|}{ Smoking years } \\
\hline$<15$ & 6 & 17.6 & 3 & 9.1 & 1.085 & 0.581 \\
\hline $15-29$ & 9 & 26.5 & 9 & 27.3 & & \\
\hline$\geq 30$ & 19 & 55.9 & 21 & 63.6 & & \\
\hline \multicolumn{7}{|l|}{ Pack - years } \\
\hline$\leq 20$ & 19 & 55.9 & 13 & 39.4 & 1.825 & 0.224 \\
\hline$>20$ & 15 & 44.1 & 20 & 60.6 & & \\
\hline \multicolumn{7}{|c|}{ Previous cessation attempts } \\
\hline Yes & 23 & 67.6 & 27 & 81.8 & 1.776 & 0.183 \\
\hline No & ॥ & 32.4 & 6 & 18.2 & & \\
\hline \multicolumn{7}{|c|}{ Method used in the previous attempt } \\
\hline No Intervention & ॥ & 32.4 & 6 & 18.2 & 5.681 & 0.128 \\
\hline Self-willed & 21 & 61.8 & 20 & 60.6 & & \\
\hline With drug support & 2 & 5.9 & 3 & 9.1 & & \\
\hline Other (Acupuncture etc.) & 0 & 0 & 4 & 12.1 & & \\
\hline \multicolumn{7}{|c|}{ Encouragement of close friends in the cessation attempt } \\
\hline They encourage & 16 & 47.1 & 20 & 60.6 & & \\
\hline Do not encourage & ॥ & 32.4 & 7 & 21.2 & 1.396 & 0.498 \\
\hline Partially encourage & 7 & 20.6 & 6 & 18.2 & & \\
\hline \multicolumn{7}{|c|}{ Fagerström Nicotine Dependence Test (FNDT) } \\
\hline Very low $(0-2$ p.) & 1 & 2.9 & 3 & 9.1 & 6.730 & 0.151 \\
\hline Low (3-4 p.) & 9 & 26.5 & 2 & 6.1 & & \\
\hline Medium (5 p.) & 4 & 11.8 & 6 & 18.2 & & \\
\hline High (6-7 p.) & 10 & 29.4 & 14 & 42.4 & & \\
\hline Very high (8-10 p.) & 10 & 29.4 & 8 & 24.2 & & \\
\hline
\end{tabular}

TABLE 3. Self-efficacy Questionnaire (SEQ) scores at first and last interviews

\begin{tabular}{|c|c|c|c|c|}
\hline & $\begin{array}{c}\text { Intervention } \\
\quad(n=34)\end{array}$ & $\begin{array}{l}\text { Control } \\
(n=33)\end{array}$ & $t$ & $p$ \\
\hline \multicolumn{5}{|l|}{ SEQ scores $(X \pm S D)$} \\
\hline First Interview (SEQI) & $59.94 \pm 17.17$ & $62.93 \pm 14.94$ & -0.762 & 0.449 \\
\hline Last Interview (SEQ2) & $113.82 \pm 19.37$ & $101.06 \pm 14.94$ & 2.356 & 0.021 \\
\hline Score Differences (SEQ2-SEQI) & $53.88 \pm 27.50$ & $38.12 \pm 24.03$ & 2.495 & 0.015 \\
\hline
\end{tabular}

and "when stressed" and during "arguments" after cessation. The control group also stated that before cessation, their desire was strongest "postprandial" and "when stressed". Except for "Coffee" and "popular smoking places", no statistically significant differences were determined between the groups after cessation attempt ( $p>0.05)$.

At the end of the study, it was observed that $88.2 \%$ of the intervention group and $60.6 \%$ of the control group had ceased smoking, and a statistically significant difference was determined $(p<0.05)$. The intervention group was 1.5 times more successful compared to the control group at the end of the sixth month. Among participants who had not tried any previous cessation attempts, the intervention group was 5.5 times more successful than the control group. Among participants who had tried previous cessation attempts, the intervention

TABLE 4. Smoking Abstinence Statuses of the Intervention and Control groups at the $1 s t, 3^{\text {rd }}$, and $6^{\text {th }}$ month periods

\begin{tabular}{|c|c|c|c|c|}
\hline \multirow[b]{2}{*}{ Characteristics } & \multicolumn{2}{|c|}{ Ceased Smoking \% } & \multirow[b]{2}{*}{ RE } & \multirow[b]{2}{*}{$\% 95 \mathrm{Cl}$} \\
\hline & Intervention & Control & & \\
\hline \multicolumn{5}{|l|}{ All the Participants } \\
\hline At the end of $I^{\text {st }}$ month & 97.1 & 90.9 & 1.068 & $0.944-1.207$ \\
\hline At the end of $3^{\text {rd }}$ month & 97.1 & 84.8 & 1.144 & $0.979-1.336$ \\
\hline At the end of $6^{\text {th }}$ month & 88.2 & 60.6 & 1.456 & $1.077-1.968$ \\
\hline \multicolumn{5}{|c|}{ Previous Cessation Attempt Exists } \\
\hline At the end of $I^{\text {st }}$ month & 95.7 & 92.6 & 1.033 & $0.900-1.186$ \\
\hline At the end of $3^{\text {rd }}$ month & 95.7 & 88.9 & 1.076 & $0.918-1.262$ \\
\hline At the end of $6^{\text {th }}$ month & 87.0 & 70.4 & 1.236 & $0.923-1.654$ \\
\hline \multicolumn{5}{|c|}{ Previous Cessation Attempt Does Not Exist } \\
\hline At the end of $I^{\text {st }}$ month & 100 & 83.3 & 1.200 & $0.839-1.716$ \\
\hline At the end of $3^{\text {rd }}$ month & 100 & 66.7 & 1.500 & $0.852-2.641$ \\
\hline At the end of $6^{\text {th }}$ month & 90.9 & 16.7 & 5.455 & $0.903-32.963$ \\
\hline \multicolumn{5}{|c|}{ Cigarettes per day $\leq$ l pack (20 pieces) } \\
\hline At the end of $I^{\text {st }}$ month & 95.2 & 84.2 & |.|13| & $0.910-1.405$ \\
\hline At the end of $3^{\text {rd }}$ month & 95.2 & 73.7 & 1.293 & $0.972-1.719$ \\
\hline At the end of $6^{\text {th }}$ month & 85.7 & 52.6 & 1.629 & $1.027-2.582$ \\
\hline
\end{tabular}

Cigarettes per day $>$ I pack (20 pieces)

$\begin{array}{llllc}\text { At the end of } \mathrm{st}^{\text {st }} \text { month } & 100 & 100 & - & - \\ \text { At the end of } 3^{\text {rd }} \text { month } & 100 & 100 & - & - \\ \text { At the end of } 6^{\text {th }} \text { month } & 92.3 & 71.4 & 1.292 & 0.896-1.865 \\ \text { FNDT } \leq 5 & & & & \\ \text { At the end of }\left.\right|^{\text {st }} \text { month } & 92.9 & 72.7 & 1.277 & 0.864-1.886 \\ \text { At the end of } 3^{\text {rd }} \text { month } & 92.9 & 72.7 & 1.277 & 0.864-1.886 \\ \text { At the end of } 6^{\text {th }} \text { month } & 92.9 & 45.5 & 2.043 & 1.052-3.966 \\ \text { FNDT } \geq 6 & & & & \\ \text { At the end of }\left.\right|^{\text {st }} \text { month } & 100 & 100 & - & - \\ \text { At the end of } 3^{\text {rd }} \text { month } & 100 & 90.9 & 1.100 & 0.964-1.255 \\ \text { At the end of } 6^{\text {th }} \text { month } & 85.0 & 63.6 & 1.336 & 0.927-1.925\end{array}$

RE: Relative effectiveness; Cl: Confidence Interval; FNDT: Fagerström Nicotine Dependence Test 
group was 1.2 times more successful than the control group. Among the individuals who smoked less than a pack per day, the intervention group was l.6 times more successful than the control group. All participants in both groups who smoked more than a pack per day managed to avoid smoking at the end of the first and third months. But at the end of the sixth month, the intervention group was 1.3 times more successful than the control group. Among the individuals with a dependence score of 5 or less, it was observed that the intervention group was 2 times more successful than the control group at the end of the sixth month. Among the individuals with a dependence score of 6 or more, the intervention group was 1.3 times more successful than the control group at the end of the sixth month (Table 4).

\section{DISCUSSION}

Nicotine is a challenging addiction, and relapse is one of the biggest problems in smoking cessation. Relapse prevention interventions and smoking cessation interventions are different, but they cannot be separated from one another. Smoking cessation interventions focus on cessation, whereas relapse interventions focus on prevention, especially of smoking resumption (22). Although data about relapse prevention indicate a wide variation, in a systematic review, it was stated that pharmacotherapy and written materials were effective in the short term, and behavioral interventions were effective in the long term (23). In the literature, a combination of behavioral counseling and pharmacotherapy have been found to produce the best results $(3,8)$. The likelihood of success increased by between $10 \%$ and $25 \%$ when the level of behavioral support increased (9). In our study, participants who decided to quit received supplemental monitoring and counseling along with pharmacotherapy and routine monitoring in the smoking cessation clinic. At the end of the sixth month, it was determined that $88.2 \%$ of the intervention group and $60.2 \%$ of the control group ceased smoking $(p<0.05)$. In studies in Turkey that evaluated data from smoking cessation therapies, cessation rates were reported as 36\%-65\% after three months and $22 \%-45 \%$ after the first year (24-26). In our study, the intervention group's cessation rates were higher than those rates. In a study conducted in 2010 at a smoking cessation clinic, Önen et al. (27) observed that behavioral therapy applied with pharmacologic treatments was more effective than other therapies, and they recommended routine monitoring and support with behavioral treatments.

According to randomized trials, there is a strong dose-response relationship between the duration of counseling and abstinence rates $(3,28)$. Intensive counseling is more effective if there are at least four sessions longer than 10 minutes (3). Joseph et al. (29) stated that intensive counseling providing long-term social support was effective in smoking cessation and relapse prevention. In our study, the intervention group attended an average of 5.5 follow-ups and the control group an average of 4; the results were significantly different. Argüder et al. (25) stated that the low success rate in their clinic may have been because of the failure of participants to attend follow-ups after the first interview.

It is important to identify factors that may increase the risk of smoking or relapse. These factors include stressful conditions, spending time with other smokers, alcohol consumption, and smoking triggers (e.g., drinking coffee and after a meal) (3). In our study, risk factors were identified during the first interview, and coping strategies were determined based on individual needs. Individuals in the intervention group stated that they most desired to smoke "postprandial" and "when stressed" before the cessation attempt and "when stressed" and "when in arguments" after cessation. In the previous interviews, participants were asked to note smoking triggers and coping strategies in a "smoking diary" in order to identify and manage their own triggers. Similarly, Sağlam (26) determined the "eating" factor was a key trigger. Joseph et al. (29) investigated high-risk situations for relapse and planned interventions that were designed to cope with them.

It is important to practice coping skills to deal with the dangerous situations once these have been defined. Appropriate encouragement and support should be given to maintain healthy practices (3). In our study, participants in the intervention group who relapsed were advised to regard the relapse cigarette as their last, to consider this as a learning experience, and to continue their visits. At the end of the sixth month, the greater effectiveness in the intervention group compared to the control group was noticeable. The greater rate of relapse in the control group was attributed to the lack of this support. Similarly, Joseph et al. (29) stated that intensive follow up resulted in greater success compared to standard follow up in the long term. Deiches et al. (30) determined that in the first eight weeks of smoking cessation, the relapse rate was as high as $63 \%$, and that $78 \%$ of those who relapsed in the early period restarted smoking within about six months.

According to Bandura, self-efficacy was one of the most important criteria for quitting smoking (I0). Studies also showed that there was a positive correlation between self-efficacy scores and the time after quitting $(|0,3|-33)$. In our study, increases in the self-efficacy scores were greater in the intervention group than those in the control group.

In the literature, it has been reported that long-term smokers who started smoking early are more prone to failure in smoking cessation (4). According to the Global Adult Tobacco Survey, approximately half of all smokers attempted to quit, but only $15.8 \%$ succeeded (34). Önen et al. (27) stated that unsuccessful cessation attempts do not adversely affect the success rates of future cessation attempts, but in our study, the intervention was 1.2 times more effective in participants with a history of cessation attempts but 5.5 times more effective in those without a history when compared to results for the control group. When the intervention group rates compared to rates for similar groups of participants in the control group, the cessation success rates of intervention group were 1.6 times greater for individuals smoking a pack or less a day; I.3 times greater for individuals smoking more than a pack a day; 2 times greater for those with a dependence score of 5 or less, and I.3 times greater for those with a dependence score of 6 or more.

\section{Conclusion and Practice Implications}

In our study, we studied the effects of supplemental monitoring and counseling in addition to the standard monitoring during the treatment period on the abstinence behavior of smoking cessation center applicants. At the end of the six months, the 
self-efficacy score of the intervention group was significantly higher than that in the control group. The intervention group was 1.5 times more successful than the control group in smoking cessation. Individuals who have been successful in smoking cessation should be frequently monitored, and in follow-ups simultaneously supported by physicians, nurses, and other healthcare providers. There is a need for longer-term, randomized controlled studies with larger sample groups.

\section{Study Limitations}

Individuals who were successful in smoking cessation were monitored for only six months. All procedures performed in studies involving human participants were in accordance with the ethical standards of the institutional and/or national research committee and with the 1964 Helsinki declaration and its later amendments or comparable ethical standards.

Ethics Committee Approval: Ethics committee approval was received for this study from Ethics committee approval received for this study from Gulhane Military Medical Academy (Approval Date: May, 2012, Approval Number: |49|-1323-12/1648-4002)

Informed Consent: Written informed consent was obtained from patients who participated in this study.

Peer-review: Externally peer-reviewed

Author contributions: Concept - A.G., T.Y., H.B.; Design - A.G., T.Y., H.B.; Supervision - A.G., T.Y., H.B.; Resource - A.G., T.Y., H.B.; Materials - A.G., T.Y., H.B.; Data Collection and/or Processing - A.G., T.Y., H.B.; Analysis and/ or Interpretation A.G., T.Y., H.B.; Literature Search A.G., T.Y., H.B.; Writing - A.G., T.Y., H.B.; Critical Reviews - A.G., T.Y., H.B.

Conflict of Interest: The authors have no conflicts of interest to declare.

Financial Disclosure: The authors declared that this study has received no financial support.

\section{REFERENCES}

I. Ergüder T. Tobacco Use and Prevention Programs. In: Current issues and approaches related to public health. Editor: Aslan D. Ankara. 2009; 22-25. (in Turkish)

2. Yorgancıoğlu A, Esen A. Nicotine dependence and physicians. Turk Thorac J 2000; I(I): 90-5.

3. Park ER. Behavioral approaches to smoking cessation. Literature review current through: 2016 Sep: Topic 6920 Version 27.0. UpToDate. 2016; (cited 25 October 2016) Available forom: URL: https:// www.uptodate.com/contents/behavioral-approaches-to-smoking-cessation

4. Hwang G-S, Jung H-S, Yi Y, Yoon C, Choi J-W. Smoking cessation intervention using stepwise exercise incentives for male workers in the workplace. Asia Pac J Public Health 20I2; 24(I): 82-90. [CrossRef]

5. Caponnetto P, Keller E, Bruno CM, Polosa R. Handling relapse in smoking cessation: strategies and recommendations. Intern Emerg Med 20I3; 8(I): 7-I2. [CrossRef]

6. Shiffman S, Kassel J, Gwaltney C, McChargue D. Relapse prevention for smoking. In: Marlatt GA, Donovan DM, editors. Relapse prevention: Maintenance strategies in the treatment of addictive behaviors. New York, the USA. The Guilford Press; 2005. pp. 92129

7. Marlatt GA, George WH. Relapse prevention: Introduction and overview of the model. Br J Addict 1984; 79(3): 26I-73. [CrossRef]

8. VA/DoD clinical practice guideline for the management of tobacco use, US National Guideline Clearinghouse. 2004; [cited 25 Oc- tober 2016]. Available from: URL: http://www.healthquality.va.gov/ tuc/tuc_poc.pdf

9. Stead LF, Koilpillai P, Lancaster T. Additional behavioral support as an adjunct to pharmacotherapy for smoking cessation. Cochrane Database System Review. 2015; CD009670. [CrossRef]

10. Yalçınkaya-Alkar Ö, Karanci AN. What are the differences in decisional balance and Self-Efficacy between Turkish smokers in different stages of change? Addict Behav 2007; 32(4): 836-49. [CrossRef]

II. Demir T. Structuring smoking cessation policlinic, [cited 25 October 2016]. Available from: URL: http://www.toraks.org.tr/userfiles/file/ SiGARA_BIRAKTIRMA_PLK_YAPILANDIRILMASI-Tuncalp_Demir. pdf.

12. Lemmens $\vee$, Oenema $A$, Knut IK, Brug J. Effectiveness of smoking cessation interventions among adults: a systematic review of reviews. Eur J Cancer Prev 2008; 17(6): 535-44. [CrossRef]

13. Young JM, Girgis S, Bruce TA, Hobbs M, Ward JE. Acceptability and effectiveness of opportunistic referral of smokers to telephone cessation advice from a nurse: a randomised trial in Australian General Practice. BMC Fam Pract 2008; 9: 16. [CrossRef]

14. Karatay G, Kubilay G, Emiroğlu ON. Effect of motivational interviewing on smoking cessation in pregnant women. J Adv Nurs 20I0; 66(6): 1328-37. [CrossRef]

15. Sreedharan J, Muttappallymyalil J, Venkatramana M. Nurses' attitude and practice in providing tobacco cessation care to patients. $J$ Prev Med Hyg 20I0; 5I(2): 57-6I.

16. Rice $V$, Hartman-Boyce J, Stead L. Nursing interventions for smoking cessation. Cochrane Database System Review. 2013; 12:CD001188. [CrossRef]

17. Ruger JP, Weinstein MC, Hammond SK, Kearney MH, Emmons KM. Cost-effectiveness of motivational interviewing for smoking cessation and relapse prevention among low-income pregnant women: a randomized controlled trial. Value Health 2008; II(2): 191-8. [CrossRef]

18. Zwar NA, Richmond RL, Forlonge G, Hasan I. Feasibility and effectiveness of nurse-delivered smoking cessation counselling combined with nicotine replacement in Australian General Practice. Drug Alcohol Rev 20Il; 30(6): 583-8. [CrossRef]

19. Heatherton TF, Kozlowski LT, Frecker RC, Fagerstrom KO. The Fagerstrom test for nicotine dependence: a revision of the Fagerstrom Tolerance Questionnaire. Br J Addict 1991; 86(9): III9-27. [CrossRef]

20. Uysal, MA, Kadakal F, Karsidag C, Bayram NG, Uysal O, Yilmaz V. Fagerstrom Test for nicotine dependence: reliability in a Turkish sample and factor analysis. Tuberk Toraks 2004; 52(2): II5-2I.

21. Velicer WF, Prochaska JO. A comparison of four self-report smoking cessation outcome measures. Addict Behav 2004; 29(I): 5I-60. [CrossRef]

22. Mayer C, Vandecasteele H, Bodo M, Primo C, Slachmuylder JL, Kaufman $\mathrm{L}$, et al. Smoking relapse prevention programs and factors that predict abstinence: a controlled study comparing the efficacy of workplace group counselling and proactive phone counselling. J Smok Cessat 2010; 5(I): 83-94. [CrossRef]

23. Agboola S, McNeill A, Coleman T, Bee JL. A systematic review of the effectiveness of smoking relapse prevention interventions for abstinent smokers. Addiction 2010; 105(8): 1362-80. [CrossRef]

24. Solak ZA, Telli CG, Erdinç E. Results of smoking cessation program. Turk Thorac J 2003; 4(I): 73-7.

25. Argüder E, Karalezli A, Hezer H, Kılıç H, Er M, Hasanoğlu HC, et al. Factors affecting the success of smoking cessation. Turk Thorac $J$ 2013; 14(3): 8I-7. [CrossRef]

26. Sağlam L. Investigation of the results of a smoking cessation clinic and the factors associated with succes. Turk J Med Sci 2012; 42(3): $515-22$.

27. Önen ZP, Șen E, Gülbay BE, Öztürk A, Akkoca Yıldız Ö, Acıcan T, et al. Comparing the effectiveness of different treatment modalities on the smoking cessation rates. Tuberk Toraks 2010; 58(4): 385-92. 
28. Small RE, Kennedy DT. Methods to facilitate smoking cessation: guidelines and treatment modalities. Medscape. 2018 July (cited 201810 July). Available from: URL: https://www.medscape.org/ viewarticle/4|853|

29. Joseph AM, Fu SS, Lindgren B, Rothman AJ, Kodl M, Lando $H$, et al. Chronic disease management for tobacco dependence: a randomized, controlled trial. Arch Intern Med 20II; 17I: 1894-900. [CrossRef]

30. Deiches JF, Baker TB, Lanza S, Piper ME. Early Lapses in a Cessation Attempt: Lapse contexts, cessation success, and predictors of early lapse. Nicotine Tob Res 2013; I5(II): 1883-91. [CrossRef]
31. Karatay G, Kubilay G, Emiroğlu ON. Effect of motivational interviewing on smoking cessation in pregnant women. J Adv Nurs 20I0; 66(6): 1328-37. [CrossRef]

32. Gwaltney CJ, Metrik J, Kahler CW, Shiffman S. Self-efficacy and smoking cessation: a meta-analysis. Psychol Addict Behav 2009; 23(I): 56-66. [CrossRef]

33. Dijkstra A, Vries HD. Self-Efficacy expectations with regard to different tasks in smoking cessation. Psychology and Health 2000; I5(4): 50I-II. [CrossRef]

34. Turkey Global Adult Tobacco Survey Report 2012. Turkish Ministry of Health, Turkish Public Health Agency. Ankara: Anıl Publisher; 20l4.p:l-4. 